\title{
Workforce Participation, Ageing, and Economic Welfare: New Empirical Evidence on Complex Patterns across the European Union
}

\author{
Mirela S. Cristea $\mathbb{D}^{1},{ }^{1}$ Marilen G. Pirtea ${ }^{D},{ }^{2}$ Marta C. Suciu ${ }^{D},{ }^{3}$ and Gratiela G. Noja ${ }^{4}{ }^{4}$ \\ ${ }^{1}$ Department of Finance, Banking and Economic Analysis, Faculty of Economics and Business Administration, \\ University of Craiova, 200585 Craiova, Romania \\ ${ }^{2}$ Department of Finance, Faculty of Economics and Business Administration, West University of Timisoara, \\ 300115 Timisoara, Romania \\ ${ }^{3}$ Department of Economics and Economic Policies, Faculty of Theoretical and Applied Economics, \\ The Bucharest University of Economic Studies, 010374 Bucharest, Romania \\ ${ }^{4}$ Department of Marketing and International Economic Relations, Faculty of Economics and Business Administration, \\ West University of Timisoara, 300115 Timisoara, Romania \\ Correspondence should be addressed to Gratiela G. Noja; gratiela.noja@e-uvt.ro
}

Received 17 November 2021; Accepted 24 December 2021; Published 6 January 2022

Academic Editor: S.S. Askar

Copyright ( $) 2022$ Mirela S. Cristea et al. This is an open access article distributed under the Creative Commons Attribution License, which permits unrestricted use, distribution, and reproduction in any medium, provided the original work is properly cited.

\begin{abstract}
The ageing population has become one of the major issues, with manifold consequences upon the economic welfare and elderly living standards satisfaction. This paper grasps an in-depth assessment framework of the ageing phenomenon in connection with the labor market, with significant implications upon economic welfare, across the European Union (EU-27). We configure our research on four distinctive groups of the EU-27 countries based on the Active Ageing Index mapping, during 1995-2018, by acknowledging the different intensities of ageing implications on economic well-being from one group of countries to another. The methodological endeavor is based on Structural Equation Modelling. Empirical results highlight that the ageing dimensions and labor market productivity notably shape the socioeconomic development of EU countries, visibly distinguished across the four panels. The economic development induced remarkable positive spillover effects on the welfare of older people, under the influence of the ageing credentials and dynamic shaping factors. Our research advances the literature underpinnings on this multifaceted topic by investigation made on specific groups of the EU countries and distinctive strategies proposed for each group of countries, as effective results for improving the well-being of older people. Constant policy rethinking and adequate strategies should be a top priority for each specific group of EU countries, to further sustain the ageing phenomenon, with positive implications mostly on elderly welfare.
\end{abstract}

\section{Introduction}

In all countries all over the world, the demographic studies entail that a series of societal challenges have emerged, where elderly cohorts are increasing at a steady pace and are expected to continue growing over the following decades [1]. Thus, the ageing population, which means the increasing of life expectancy and decreasing of birth rates, has become a major issue, affecting the labor market equilibrium and, also, the welfare of older people, mainly, due to a weak viability and sustainability of the pension funds [2], health deterioration, or lower social involvement [3-6].

As a result of these tendencies, the population composition has changed and, in the coming years, even more notable mutations are expected to occur, from the pyramidshaped frame, with the basis of people aged 0-16 years, more numerous than the people aged over 65 , representing upper segments, to a representation of "a rectangular pattern" [7] (p. 4) [8]. As regards Europe, which becomes the oldest continent in the world, the European Union (EU) has 
registered the highest old-age dependency ratio $(65+/$ (15-64)), representing $31 \%$ in 2019 , compared to $13.95 \%$ at the worldwide level [9], being projected to increase at $57 \%$ in 2100 [10]. As much, against the background of a declining active labor force (15-64 years), the implications of demographic ageing on economic and social well-being are more and more visible within all countries, but with different intensities [5, 11-15]. This requires an accurate and specific analysis by distinct groups of countries with similar characteristics.

Therefore, the ageing phenomenon and socioeconomic welfare approaches at the EU level have been highly debated previously within the literature, but their integrative impact has been less considered, as far as we know especially for the four specific groups of the EU Member States (MS).

In front of these facts and challenges, the main aim of our paper is to assess the ageing phenomenon in connection with the labor market implications in terms of socioeconomic welfare within the EU-27 MS, widened with an in-depth analysis for the four distinctive EU-27 MS groups. We have excluded the United Kingdom (UK), due to the Brexit final outcomes. The analyzed groups (panels) are mapped according to the United Nations Economic Commission for Europe (UNECE)/European Commission (EC) [16], considering the Active Ageing Index (AAI). We have accounted for the four panels of EU MS in our investigation (that correspond to the groups/clusters marked by the UNECE/EC [16] with blue, green, red, and yellow colours), in order to propose a mix of specific policies and strategies for each group of countries, as Walker and Zaidi [17] also recommended as effective results. In our research, we applied Structural Equation Modelling (SEM) for an integrative measurement approach (direct, indirect, and total) of the interlinkages between the ageing phenomenon and labor market factors (under the influence of specific selected economic and social variables) upon economic development and poverty alleviation of older people (65+). The analyzed period is 1995-2018.

The paper is organized as follows: after a concise introduction on the subject, centered on the importance of the ageing phenomenon within the economic and social framework at the level of the EU and, more specific, for the four groups of MS considered in the empirical analysis, a synthesized brief literature review is accomplished. This section is split in two parts: the main policies adopted, particularly within the EU area, at regional and local levels, and state of the art on the ageing phenomenon and labor market integration within the economic welfare context. Thereafter, we present the selected data for the empirical investigation, the research methodology applied, and the scientific hypotheses. Discussions of the obtained results follow further, which are summarized within the concluding remarks. Extensive information regarding the empirical evidence is enclosed within Appendix.

\section{Literature Review: Theoretical Framework}

2.1. Ageing Phenomenon and Key Policies to Promote Active Ageing Management Support. All around the world, there are numerous notices and recommendations regarding the awareness of ageing implications in all facets of life (health, life satisfaction, financial support, social involvement, and education). Thus, as World Health Organization (WTO) [8] (p. 6) underlines, population ageing "is one of humanity's greatest triumphs," which entails its awareness and support by policymakers, promoting healthy and active ageing management strategies as an important requirement among all countries.

The Organization for Economic Cooperation and Development (OECD) proposes as recommendations, even since 2006, the need to introduce "age-friendly" policies, as "part of a broader strategy for responding to the challenges of population ageing" [1] (p. 13). Due to significant increases in life expectancy that exceed the birth rate, the older workforce (aged 55-64) is greater than the previous years, but the age of exit of the labor market became lower than in the past [18]. Therefore, the main goals of the policymakers, proposed by the OECD, should underline the importance of working ageing support, striving towards offering elderly individuals a higher degree of opportunities and options in regard to working environments $[1,18]$.

At the level of the EU, as a response to the ageing phenomenon, a series of the MS have started to adopt and implement measures that are in line with the OECD stated goals of continuous employment of elderly workers, enclosed within 55-64 years' cohort. Thus, starting with the year 2012, the EU pays a particular attention to active ageing management strategies, through specific policies and measures addressed to all MS.

These strategies and policies are designed such as to better hinder the negative implications upon older people's life satisfaction and welfare. In this vein, as one of the policy tools or instruments, "the Active Ageing Index (AAI)" was built and tested to discover and evaluate the unexploited potential for older people's well-being $[3,19,20]$. The AAI represents a composite index that comprises 22 indicators, based on evaluation of the four life dimensions of older people's integration, namely: (i) "the employment field," which follows the employment rate of people aged between 55 and 75 years; (ii) the ways of "participation in society" voluntary, care to their younger relatives or other people in need, and political activities; (iii) "independent, healthy, and secure living" field that follows physical training and security, the way of benefit by health services, income level, poverty risk, and lifelong learning motivation and participation; and (iv) "capacity to actively age," revealed by life expectancy, healthy life, adapting to the digital society, and education [3]. The AAI was determined starting with the year 2010, at every two years. The latest available report is for the year 2018 [16], whose results were grouped in four clusters of countries, marked with different colours, as follows: cluster 1, green, that comprises ten Central and Mediterranean EU MS; cluster 2, red, which encloses six Continental and Mediterranean EU MS; cluster 3, blue, comprising seven EU MS, geographically dispersed; and cluster 4, yellow, including five countries, namely, the Nordic States (with the UK). We performed the graphical mapping of the AAI clustering for the countries considered in our empirical analysis (without $\mathrm{UK}$ ) in Stata 16 (presented in Appendix, Figure A-I). 
Cluster 1 (green) obtained a medium AAI score under the EU average (31.4 compared to 35.8 ), with the minimum value of the AAI for Greece (28.1) and the maximum one for Spain (34.1). The other three clusters registered higher AAI scores than of the EU average. Thereby, cluster 2 (red) registered an average of the AAI score upper low to the EU one (36.4 compared to 35.8), with the minimum and maximum AAI scores for Luxembourg (35.3) and France (38.4), respectively. Cluster 3 (blue) registered a medium score of AAI of 36.6 (upper medium to the EU average, of 35.8). Countries at the extremities of the AAI interval were Lithuania (33.6) and Germany (39.5). Cluster 4 (yellow) registered a medium value of the AAI of 42.8 (the highest result compared with the EU average), with the highest score for Sweden (46.9) and the lowest one for Finland (40.6) [16] (pp. 24-25). As regards the scores obtained within each cluster for the four life dimensions considered in terms of AAI evaluation, namely, "the employment," "social participation," "independent, healthy, and secure living," and "capacity to actively age," the results for the year 2018 reveal the following: cluster 1 (red) faces the biggest difficulties with the social participation domain (with over 20\% below the EU average for this field, a level of 14.1, compared with 17.9), but also with other three groups of indicators that registered values below the EU average; cluster 2 (red) registered the most challenges only for the employment domain (with over $17 \%$ below the EU average, a level of 25.7, compared with 31.1 ); cluster 3 (blue) are confronting with most challenges for social participation component (with over 15\% below the EU average, a level of 15.1, compared with 17.9), but also with independent living and capacity to actively age (being with almost 3\% under the EU average for each domain); and the cluster 4 (yellow) registered higher AAI scores for each of the four domains (being over the EU average), but with the lowest implication for the independent living component (with more than 5\% over the EU average, a level of 75.6, compared with 71.8) [16] (pp. 21, 23). According to these results, specific policies and strategies need to be enhanced for each group of countries.

Important instruments to promote adequate people's integration on the labor market are active labor market policies (ALMPs) and passive labor market policies (PLMPS). According to the European Commission [21], ALMP "covers activation measures for the unemployed and other target groups including the categories of training, job rotation and job sharing, employment incentives, supported employment and rehabilitation, direct job creation, and start-up incentives." PLMPs "cover out-of-work income maintenance and support (mostly unemployment benefits) and early retirement benefits" [21]. These policies induce positive effects on the labor market, especially in the case of the Danish labor market, the well-known Danish "flexicurity" model, which put together the employment protection and unemployment benefits, "backed with strong activation policies" [22] (p. 14). This model is adapted at the "ageing workforce" (The Eurofound, 2020), by enhancing longer working lives through a lot of incentives especially dedicated for pension funds and reduction of early retirement schemes. ALMPs in Denmark are set up "to improve job matching for older unemployed people" by "senior job schemes" sustained by the centers dedicated for the elder people's needs [23] (p. 14).

Thus, specific measures, policies, and strategies designed to sustain the ageing phenomenon, healthy, and active ageing management tools are more than necessary at the level of each EU MS, by offering better incentives to encourage longer labor market participation; decreasing benefits through public retirement schemes that incentivize employees to exit the labor market much earlier than expected; providing better tracking and accountability to the use of welfare benefits to ensure that original purposes are met and they do not provide an incentive for workers that are looking to exit the labor market early.

2.2. State of the Arts on the Ageing Phenomenon and Labor Market Integration within the Economic Welfare Context. The brief literature review highlights that there are numerous, diverse, and quite complex studies that relate the ageing phenomenon with labor productivity or socioeconomic welfare, but very few were dedicated to specific panel groups of the EU countries.

As regards the macroeconomic impact of ageing, there are "two conceptually different ways: through a higher dependency ratio (i.e., a higher proportion of retirees to workers) and through workforce ageing" [11] (p. 4).

Most studies illustrate that, regarding the demographic changes, the new pattern of the pyramid-shaped population, of rectangular type (older people $65+$ increasing more than the younger group, 0-19 years), will have an unfavorable influence on productivity and economic growth [7, 24].

As regards working ageing (55-64 aged group of employees) and productivity in Europe, a negative effect is estimated [11]. In order to restrain the unfavorable impact over labor productivity, authors [11] (p. 18) highlighted "the crucial role played by labor market reforms such as increases in active labor market policies on training or increase in the availability of medical inputs" and also older employees' training and innovation. Cristea et al. [5] deepen the analysis of the influence of employees aged 55-64 years on labor productivity on the four groups of EU countries, according to the AAI scores. Authors [5] showed that, within countries with the lowest AAI results, the ageing workforce (55-64 years) induce a downsized labor productivity, while for the other countries, with higher AAI scores, the effects are favorable.

More specifically, different age groups of employees tend to have varying levels of productive outputs. Thus, with changes brought by population ageing, the average productivity per employee might be affected sometimes to a quite significant extent, due to amassed experience accumulated over the course of active life, devaluation of knowledge and understanding, and also various tendencies manifested mostly in the cases of mental and physical accomplishment [25]. To hinder these trends, "the need to maintain the relevance of older workers' skills" becomes primary for working ageing support [25] (p. 75). Advocating this assumption, Guest and Shacklock [26] reveal the differences existing between young and old employees. Thus, to 
one side, young employees have a higher level of endurance and physical strength, easily adapt to outside stress and influences, bring more intellectual capital, and offer higher cognitive processing. On the other side, older employees are generally seen as more suitable administrators/managers, with more in-depth judgements, being more reliable and thus providing a greater turnover.

When assessing individual level productivity of the working force, a direct correlation can be observed between the level of training and education and overall productive output [27]. As regards elderly cohorts, Feyrer [27] concludes that the accumulated knowledge in the early part of active life may become outdated in time if no actions to update and adapt the existing knowledge base are undertaken on behalf of employees and employers, thus producing a potential amplification of some undesirable effects on innovation and productivity. Von Gaessler and Ziesemer [28] (p. 125) illustrated that, in sixteen OECD countries, "the optimal response to higher growth of the dependency ratio is more education to enhance productivity."

The combination of a series of factors through productive life, including a tapering off in human and intellectual capital investments, the depreciation in mental and physiological factors, and the advent of disrupting technologies, will lead to a decline in productivity after the age of 40 years, until retirement. A series of authors argue that the decline in productivity in the case of elderly employees might affect the levels of innovation and understanding and implementation of new technologies, causing a potential amplification of further disparity between expected production goals and their accomplishments [27, 29]. Jones [30] and Aksoy et al. [31] highlighted that the innovation is strongly influenced by the size of young and middle-aged groups and adversely affected by elderly groups. Therefore, the orientation and preference of people aged over 55 years for a pronounced use of the digital technologies becomes a challenge and necessity, as response to the 4th industrial revolution era $[17,32]$ and nowadays online shift working, due to SARS-CoV-2 [33].

The implications of demographic ageing on economic growth have long been researched in the literature, highlighting unfavorable implications, but with various intensity for different groups of countries.

Thus, considering the economic and demographic conditions of developed and developing countries, Bloom, Canning, and Fink [12] highlight the fact that these implications are unfavorable, more pronounced in developed countries than in developing ones, but which can be mitigated by appropriate economic and social policies. Thus, by increasing women's engagement in the labor market (because of lowering the fertility rate) and raising the retirement age, the authors [12] argue that the unfavorable influences of increasing life expectancy and reducing fertility rates on growth economic conditions will attenuate. Unfavorable implications of demographic ageing on GDP per capita are also highlighted by Fougère and Mérette [13] in their analysis designed for seven industrialized countries within OECD countries. However, the authors [13] show that, through investments in the lifelong formation of human capital, demographic ageing might bring more opportunities for economic growth than threats, results proved also by Kotschy and Sunde [14]. Using a composite indicator for economic dimension, namely, "economic complexity (EC)," based on employment data for Italian regions/provinces, and its connection with fertility rate (TFR), Innocenti, Vignoli, and Lazzeretti [34] (p. 11) proved the positive association between the dimensions, explained by the idea that "provinces characterized by higher levels of EC also had higher levels of TFR." However, Nagarajan, Teixeira, and Silva [15] show that the problem of population ageing, at present, is not only of the developed countries, but also of developing or less developed ones. In addition to the factors for increasing women's involvement in the labor market and the lifelong education of the population, also agreed by the authors [15], they stress the role of external support to less developed countries by the international organizations, through assistance health and development, and also by attracting migrants from less developed countries to the developed ones, to alleviate the effects of poverty on the elderly population in these countries.

As a summary, adequate policies and strategies are more than necessary for specific groups of countries with similar characteristic that can hamper the negative effects of old dependency ratio and ageing workforce upon economic welfare.

\section{Data and Methodology}

By reviewing the relevant literature underpinnings, we group the data into three categories of indicators, namely: welfare variables, ageing credentials, and labor market and other specific indicators.

We grouped the EU countries on four panels, following the clustering made by the UNECE/EC [16] (p. 11) according with the AAI scores for the year 2018, as follows: $1^{\text {st }}$ panel (EU-1) comprises the EU MS with AAI scores under the EU average, namely, "Greece, Croatia, Romania, Hungary, Slovenia, Poland, Bulgaria, Slovakia, Italy, and Spain" (from the lowest, Greece, to the highest, Spain); $2^{\text {nd }}$ panel (EU-2) encloses the EU countries with AAI scores upper low of the EU mean, namely, "Luxembourg, Malta, Cyprus, Austria, Belgium, and France"; $3^{\text {rd }}$ panel (EU-3) comprises the EU countries with AAI scores upper medium of the EU average score: "Lithuania, Portugal, Latvia, the Czech Republic, Estonia, Ireland, and Germany"; and $4^{\text {th }}$ panel (EU-4) has countries ranging the highest results for the AAI scores among the other EU MS, namely, "Finland, the Netherlands, Denmark, and Sweden" (except UK, due to final Brexit decision).

More specific, the variables included in our research, compiled separately for the four groups of EU MS, are (Table 1, Appendix Tables A-Ia-A-Id):

(i) Welfare Indicators. Gross Domestic Product (GDP) per capita $\left(G D P \_C\right)$; at-risk-of-poverty rate, $65+$ (POV_R_65).

(ii) Ageing Representative Indicators. Old dependency ratio (OD_65); life expectancy at birth total population $(L E)$; crude birth rate $(B R)$. 
TABLE 1: Variables comprised in the econometric models.

\begin{tabular}{|c|c|c|c|}
\hline Acronym & Explanation & Unit of measure & Database \\
\hline$G D P \_C$ & Gross Domestic Product per capita & Constant 2010 USD & $\begin{array}{c}\text { The World Bank, World } \\
\text { Development Indicators (WDI) }\end{array}$ \\
\hline$P O V \_R \_65$ & $\begin{array}{l}\text { At-risk-of-poverty rate, } 65+\text {, EU statistics on income and } \\
\text { living conditions (EU-SILC) and the European } \\
\text { Community Household Panel (ECHP) Surveys }\end{array}$ & $\%$ & $\begin{array}{l}\text { European Commission, } \\
\text { Eurostat }\end{array}$ \\
\hline$L P$ & $\begin{array}{c}\text { Labor productivity per person employed as percentage } \\
\text { from the EU-27 average }\end{array}$ & $\%(\mathrm{EU}-27=100)$ & $\begin{array}{l}\text { European Commission, } \\
\text { Eurostat }\end{array}$ \\
\hline OD_65 & $\begin{array}{l}\text { Old dependency ratio (population } 65+\text { to population } 15-64 \\
\text { years) }\end{array}$ & $\%$ & $\begin{array}{l}\text { European Commission, } \\
\text { Eurostat }\end{array}$ \\
\hline$L E$ & Life expectancy at birth, total population & Years & $\begin{array}{l}\text { European Commission, } \\
\text { Eurostat }\end{array}$ \\
\hline$B R$ & Crude birth rate & $\begin{array}{l}\text { "The ratio of the number of } \\
\text { live births per } 1000 \text { persons" }\end{array}$ & $\begin{array}{l}\text { European Commission, } \\
\text { Eurostat }\end{array}$ \\
\hline ER_55_64 & $\begin{array}{c}\text { Employment rate, 55-64 years aged group or working } \\
\text { ageing }\end{array}$ & $\%$ of total population & $\begin{array}{l}\text { European Commission, } \\
\text { Eurostat }\end{array}$ \\
\hline$E A R N$ & $\begin{array}{l}\text { Annual net earnings for "two-earner married couple, with } \\
\text { two children" }\end{array}$ & $\begin{array}{l}\text { Purchasing Power Standard } \\
\text { (PPS) }\end{array}$ & $\begin{array}{l}\text { European Commission, } \\
\text { Eurostat }\end{array}$ \\
\hline$A L M P$ & Active labor market policies & $\%$ of GDP & $\begin{array}{l}\text { European Commission, } \\
\text { Employment, Social Affairs \& } \\
\text { Inclusion }\end{array}$ \\
\hline PLMP & Passive labor market policies & $\%$ of GDP & $\begin{array}{l}\text { European Commission, } \\
\text { Employment, Social Affairs \& } \\
\text { Inclusion }\end{array}$ \\
\hline$E d u \_a c q$ & $\begin{array}{l}\text { Educational attainment of population (upper secondary, } \\
\text { postsecondary, nontertiary and tertiary education, levels } \\
\text { 3-8) (15-64 years) }\end{array}$ & $\%$ of $15-64$ years & $\begin{array}{l}\text { European Commission, } \\
\text { Eurostat }\end{array}$ \\
\hline GERD & Research and development expenditure & $\%$ of GDP & $\begin{array}{l}\text { European Commission, } \\
\text { Eurostat }\end{array}$ \\
\hline Active_pop & Active population, $15-64$ years' aged group & $\begin{array}{l}\text { Thousand persons (annual } \\
\text { averages) }\end{array}$ & $\begin{array}{l}\text { European Commission, } \\
\text { Eurostat }\end{array}$ \\
\hline
\end{tabular}

Source: authors' process.

(iii) Labor Market and Other Specific Indicators. Labor productivity per person employed, as percentage from the EU-27 average ( $L P)$; employment rate, 55-64 years' aged group or ageing workforce (ER_55_64); total labor force/active population (Active_pop); active labor market policies (ALMP); passive labor market policies $(P L M P)$; population with secondary, upper, postsecondary, and tertiary education (levels 3-8) (EDU_acq); Research and Development (R\&D) expenditures (GERD); annual net earnings $(E A R N)$.

The analyzed period is 1995-2018 and the data was collected from Eurostat [35], the Employment, Social Affairs \& Inclusion [21], and the World Development Indicators [9] databases. Graphical representation of 2018 data for main indicators is presented below as diagrams (Figures 1-3) and as traditional graphs for an adequate comparison in the Appendix (Figures A-II-A-IV).

The main welfare representative indicators (GDP_C and $\left.P O V \_R \_65\right)$ in 2018 highlight important differentials between the EU-27 MS. Most significant outcomes are accounted by the countries enclosed within the old EU-14 group (that adhered to the EU until 1995), namely: Luxembourg, Denmark, Sweden, Netherlands, Austria, and Finland, considering GDP_C (Figure 1(a)); and Slovak
Republic and Hungary (from the new EU group of countries), along with France, Denmark, Netherlands, Greece, and Luxembourg, after POV_R_65 (Figure 1(b)). The highest poverty rates of older people $(+65)$ are in countries from the new EU-13 group (which became EU MS after 2004), namely, Estonia, Latvia, Lithuania, Bulgaria, and Croatia.

With reference to the ageing selected indicators, for the year 2018, the highest birth rate (Figure 2(a)) was registered in Ireland, France, and Sweden, from the old EU-14 countries, on the one hand, and Estonia, Cyprus, and Czech Republic, from the new EU-13 countries, on the other hand. The highest life expectancy (Figure 2(b)) was in the old EU-14 MS, namely, Italy, Spain, France, and Sweden, but also in Malta and Cyprus from the new EU-13 group of countries. The highest old dependency ratio (OD_65) was registered in Italy, Greece, Germany, Finland, and Portugal, from the old EU-14 MS, and Bulgaria, from the new EU-13 group (Figure 2(c)).

The main outcome of the labor market, namely, the labor productivity per person employed, was over the average of the EU in Ireland (the highest, almost double the EU average), Luxembourg, France, Austria, Belgium and Denmark, Finland, Germany, Italy, and the Netherlands (Figure 3(a)). Considering the specific policies addressed to 


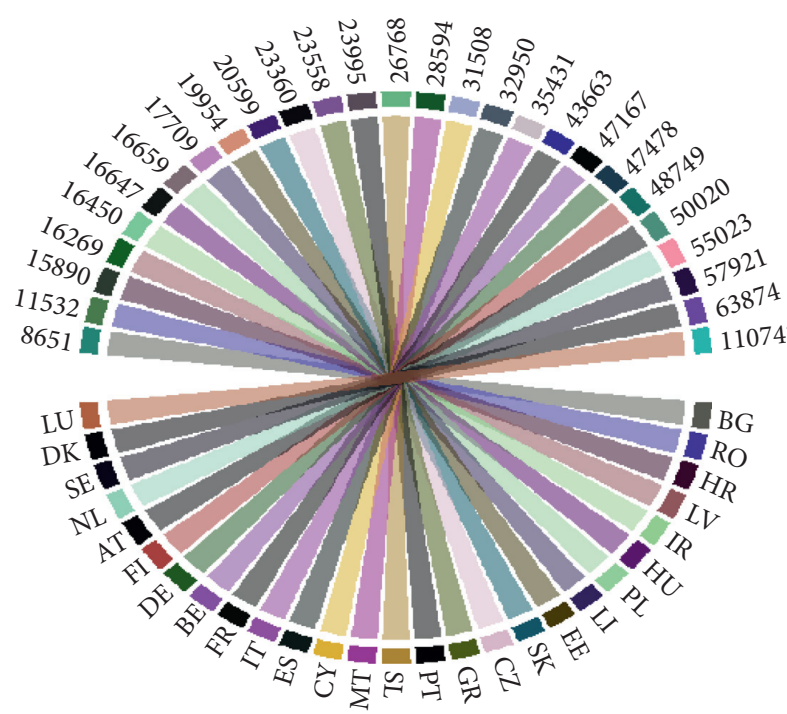

(a)

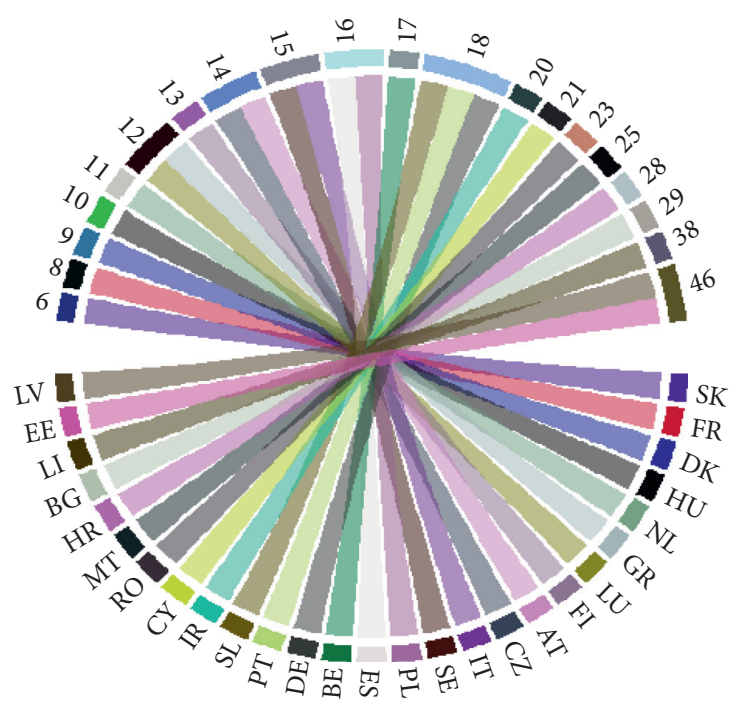

(b)

Figure 1: The welfare indicators, EU-27, 2018: (a) GDP_C. (b) POV_R_65. Source: authors' processing, data from the WDI [9] and Eurostat [35].
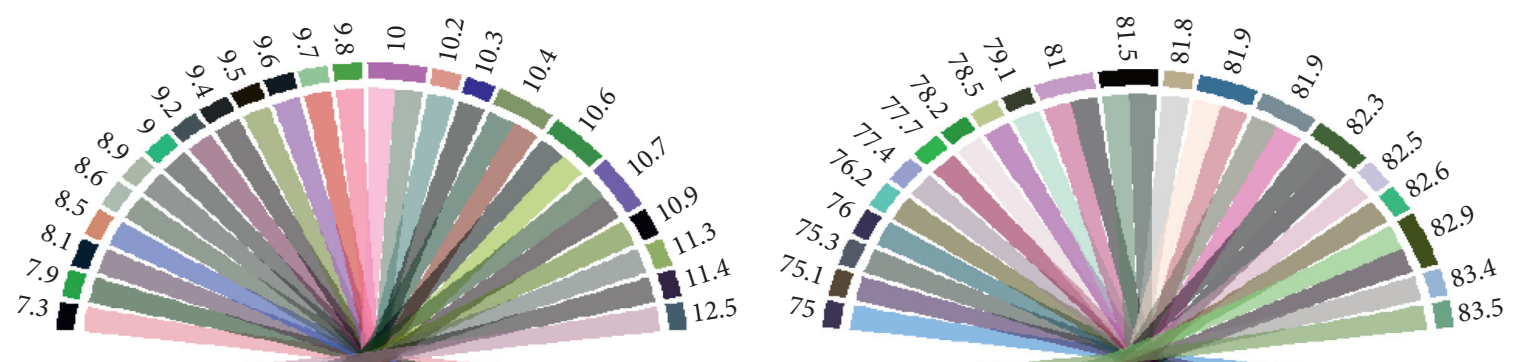

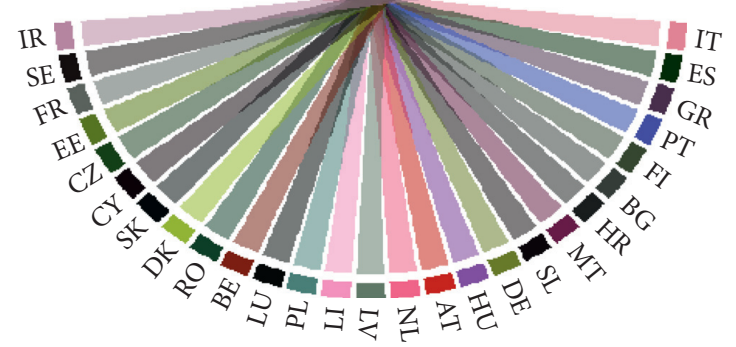

(a)

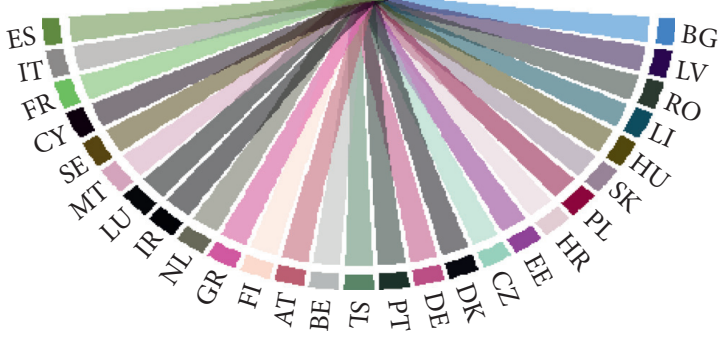

(b)
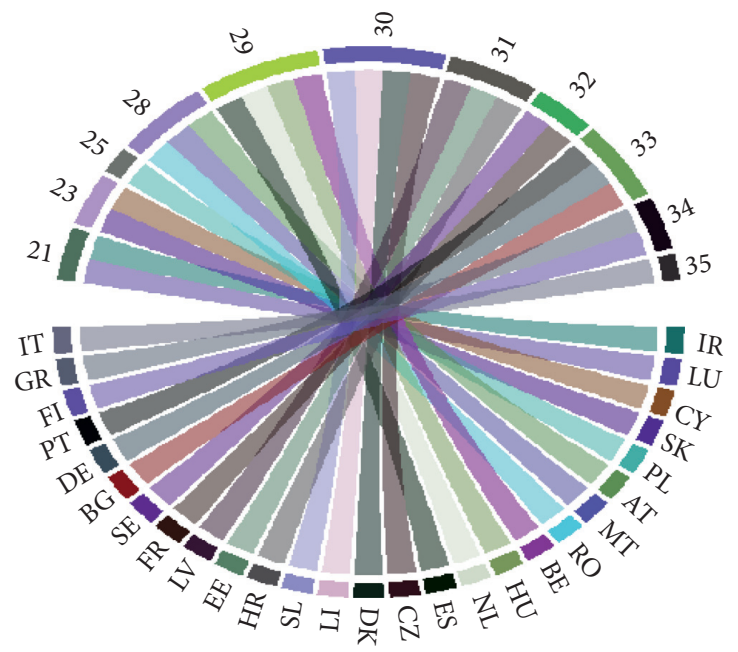

(c)

FIgUre 2: The ageing indicators, EU-27, 2018: (a) BR; (b) LE; (c) OD_65. Source: authors' processing, data from Eurostat [35]. 


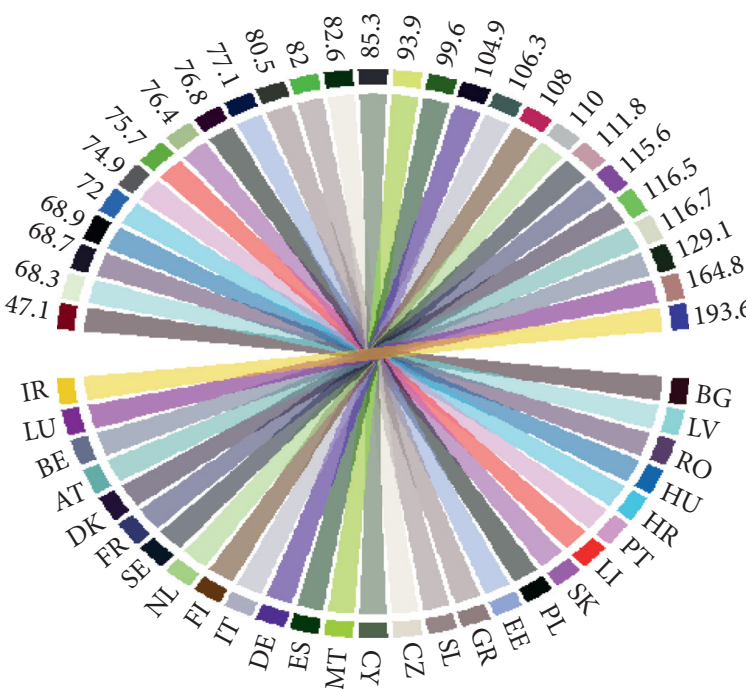

(a)
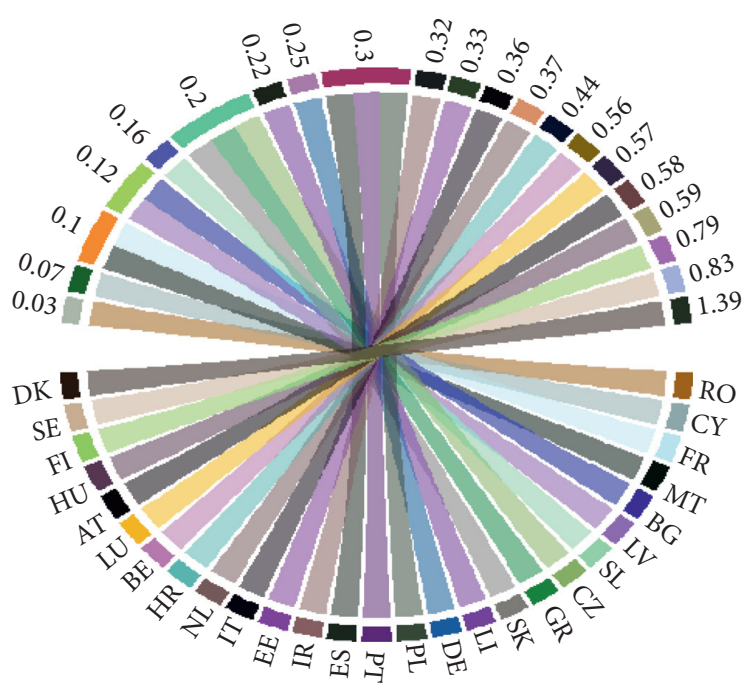

(b)

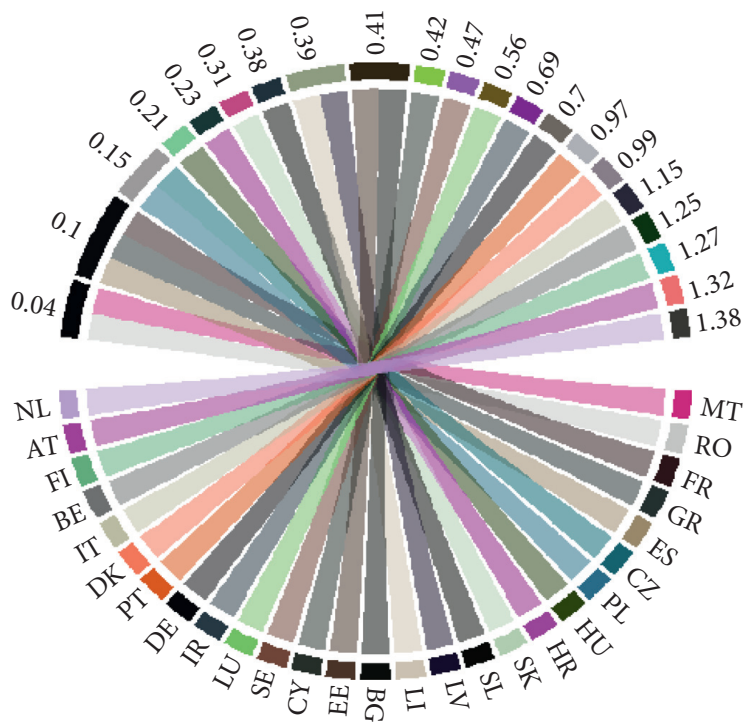

(c)

FIgURE 3: The main labor market indicators, EU-27, 2018: (a) LP; (b) ALMP; (c) PLMP. Source: authors' processing, data from Eurostat [35] and the Employment, Social Affairs \& Inclusion [21].

the labor market, namely, active labor market policies $(A L M P)$ and passive labor market policies (PLMP), the highest shares in GDP were registered in 2018 by the following countries: Denmark (1.39\% of GDP), followed by Sweden and Finland (with over $0.8 \%$ each of them), Hungary and Austria, considering ALMP (Figure 3(b)); and Finland, Denmark, Belgium, Netherlands, Austria, and Italy, considering PLMP (Figure 3(c)).

The data was stationary by logarithm to provide a proper comparability between variables. The quantitative research methodology emphasizes Structural Equation Modelling (SEM), processed in Stata 16, developed and configured on the complete sample (1995-2018) to analyze the direct, indirect, and total interlinkages between the ageing workforce (55-64 years group), labor market output (productivity), GDP per capita, and older people poverty $(65+)$, under ageing and specific economic and social variables.

These influences are considered in the open conversation on the possible trade-offs between employment of older employees and labor productivity, by also considering the inherent interlinkages with economic development, since productivity increase represents the primary source of perpetual advance in living standards and economic welfare. The general configuration of SEM model is shown in Figure 4.

SEM represents an advanced multivariate analysis technique, for appraising the overall interconnections (direct, indirect, and total) from a twofold assumption (the determinants impact interaction) between the considered variables. 


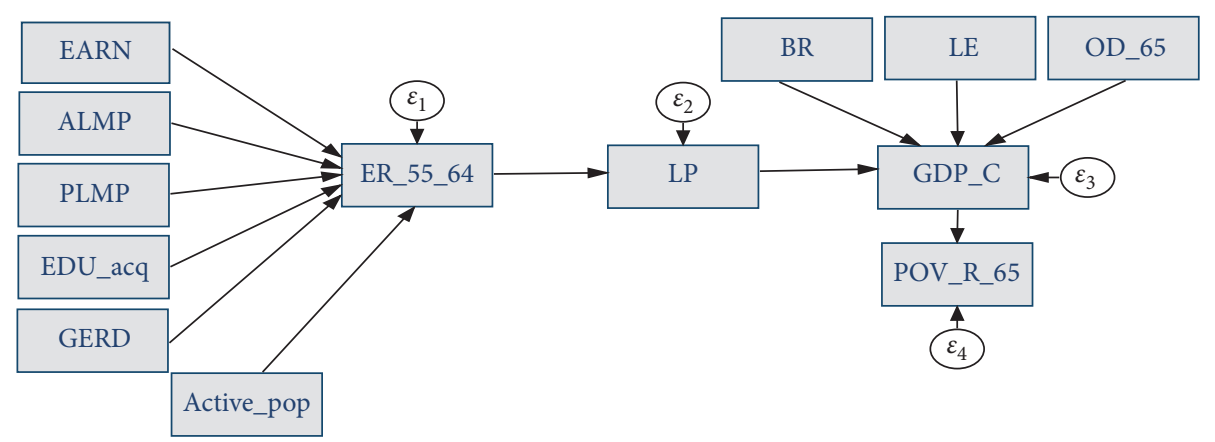

FIgURE 4: General pattern of the SEM model. Source: authors' process.

We pursue to verify the following hypotheses $(H)$ :

(i) $H_{1}$. The employment rate of the 55-64 years' aged group ("ageing workforce") represents a significant factor of influence of labor market productivity, under the impact of other economic and social factors, with relevant distinctions across the four panels of EU MS.

(ii) $H_{2}$. Ageing dimensions and labor productivity significantly shape the economic development of the EU countries, visibly distinguished across the four panels of EU MS.

(iii) $H_{3}$. There are overall (direct indirect, total) significant and diverse implications of economic development upon older people's poverty levels under the influence of the ageing credentials and labor market factors, across the four panels of EU MS.

\section{Results and Discussion}

We have built and processed the SEM models for each distinctive group of EU countries, mapped according to the UNECE/EC [16], based on the AAI. The results obtained are given in Figure 5.

To certify the results obtained, we first verified a series of particular tests, such as the Wald test for each equation (Table 2); the good-fit tests: likelihood ratio, information criteria, baseline comparison, and size of residuals which also comprises the coefficient of determination (CD) (Table 3) point out over $90 \%$ (in case of the EU-1 and EU-2 groups of countries) and $80 \%$ (in case of the EU-3 and EU-4 panels), and the older people's poverty level has been shaped by the considered variables. We have also calculated the Alpha Cronbach tests per item and per total scale that reveal the Alpha coefficients of over 0.80 , for each considered panel, which highlights a very good reliability of the scale (Table 4).

As regards the cumulative effects of the ageing workforce (ER_55_64) upon labor market productivity $(L P)$, under the influence of considered economic and social factors, a positive impact was induced only for the EU-4 panel (the Nordic States, with the best results considering AAI mapping) (Figure 5(d)) (the estimated coefficient is 0.93). The updated results for the countries with the highest AAI scores are opposite to Cristea et al. [5], which show unfavorable implications of older workforce insertion upon labor productivity. Regarding the other panels, a negative influence of ER_55_64 upon LP was entailed for the EU-3 panel (Figure 5(c)), namely, countries with upper medium AAI results, above the EU average (the estimated coefficient is -0.315), while for the EU-1 and EU-2 panels (Figures 5(a) and 5(b)), the results are favorable. These cumulative effects were accounted under the influence of EARN (positive estimated coefficients, at the highest levels for the EU-3 and EU-4 groups of countries) and ALMP (negative estimated coefficients for the EU-1, EU-2, and EU-3 panels, and a positive coefficient for the EU-4 panel). Also, there are other factors with negative effects on ER_55_64, namely: PLMP for the EU-3 and EU-4 group of countries, while for the countries with the lowest AAI results (EU-1 and EU-2), the results are slightly contradictory; Edu_acq, for the EU-1 and EU-2 group of countries, while for the countries with the highest AAI scores (EU-3 and EU-4), the educational influence is positive; total labor force (Active_pop) for the EU-1 group (the estimated coefficient is -0.0535), which entails the need for increasing the employment rate, while for the EU-3 panel, the influence is favorable (the estimated coefficient is 0.164); GERD, for the EU-3 group of countries, while for the EU-1 and EU-4, the results are positive.

Thereby, we can evidence that the 1 st hypothesis, $H_{1}$ : The employment rate of the 55-64 years' aged group ("ageing workforce") represents a significant factor of influence of labor market productivity, under the impact of other economic and social factors, with relevant distinctions across the four panels of EU MS, is fulfilled only for the countries with the highest and upper medium AAI scores.

These impacts can be hindered by increasing the participation on the labor market for the group of people aged 55-64 years with all levels of education, adapted to their abilities; reconsidering the active labor market policies, on the model of the Nordic States and the Netherlands, where the indirect influences upon $L P$ are favorable (due to the highest ALMP share in GDP), since "the results of such policies and accurate associated measures have remarkable positive effects upon the well-being on the employees and the overall economic activity" [36] (pp. 735-736); rethinking the $P L M P$, since these policies have induced negative influence on ER_55_64; for the EU-3 and EU-4 panels, reconsidering the R\&D applications (GERD) for 55-64 years' jobs creation, adapted to digital transformation and nowadays telework environment, as stated also in [11, 27, 29-31]. 


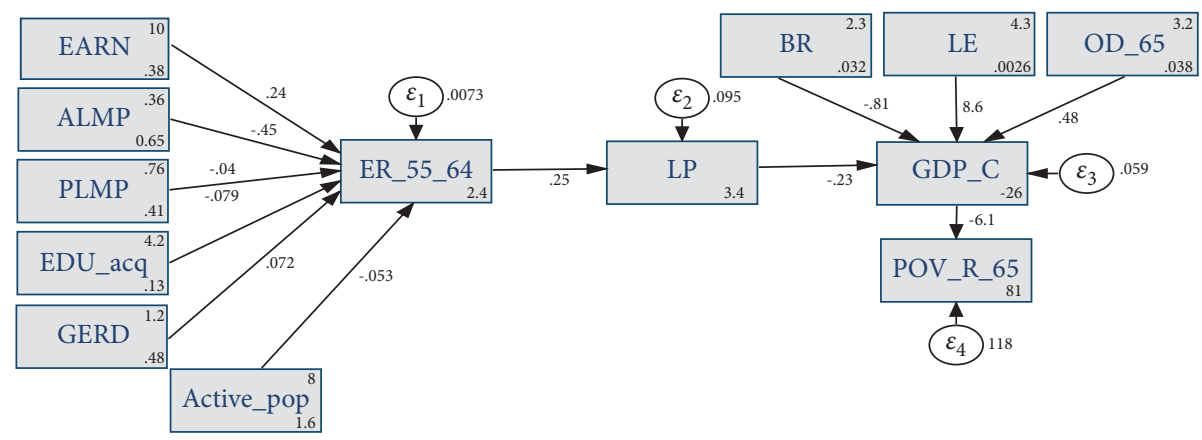

(a)

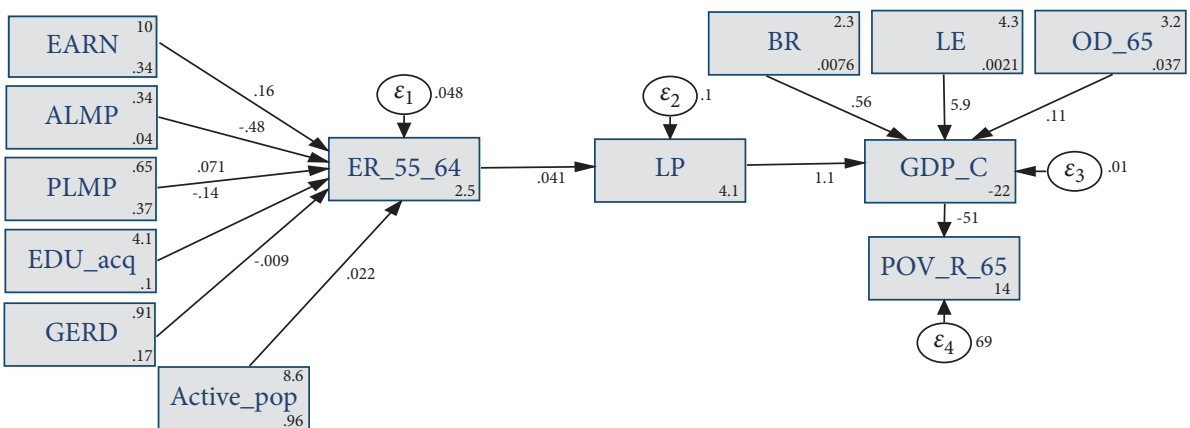

(b)

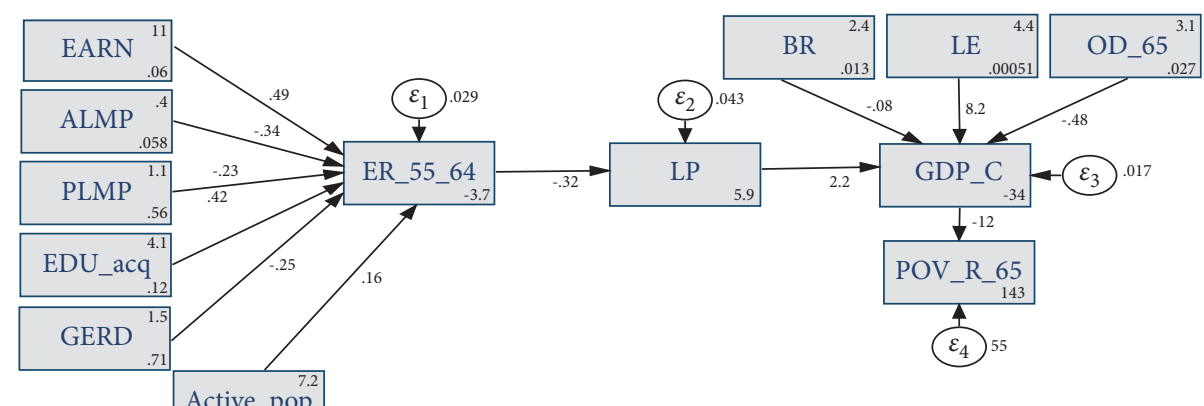

(c)

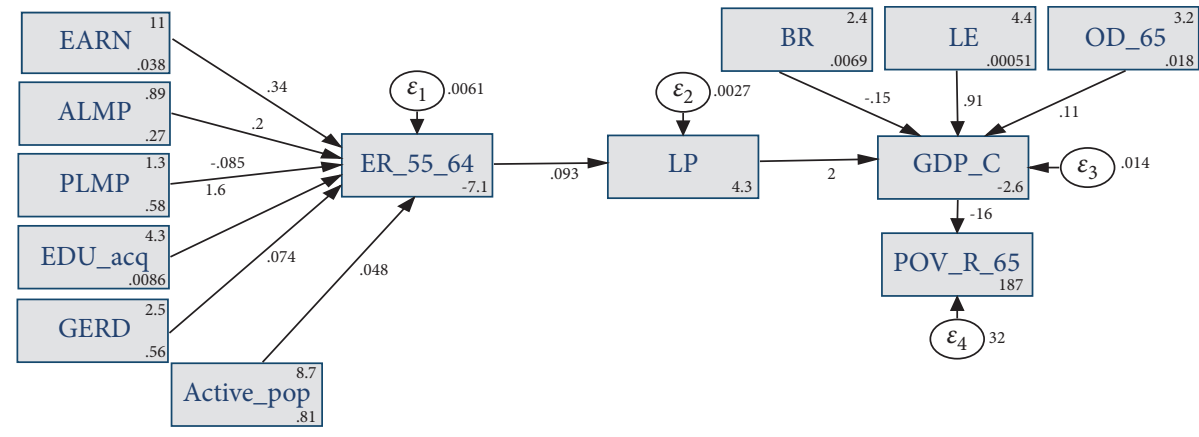

(d)

Figure 5: SEM models, 1995-2018: (a) EU-1; (b) EU-2; (c) EU-3; (d) EU-4. Source: own process.

Further, the integrative impacts of $L P$ (under direct and indirect effects of considered variables) and ageing credentials (BR, $L E$, and $\left.O D \_65\right)$ are conducted to an increase in GDP_C for the countries with AAI scores above the EU average (EU-2, EU-3 and EU-4) (the estimated coefficients are $1.055,2.241$, and 1.987, respectively) (reversed of those revealed by Fougère and Mérette [13]), while for the countries with AAI scores under the EU level, the cumulative effects are unfavorable (the estimated coefficient is -0.234 ), being similar to the results revealed by Bloom, Canning, and Fink [12]. As regards ageing credentials, for the countries with AAI scores under the EU level (EU-1) (Figure 5(a)), birth rate $(B R)$ has induced unfavorable impact on GDP_C (opposite of those proved by Innocenti, 
TABLE 2: Wald test results for the SEM models, EU-27, 1995-2018.

\begin{tabular}{|c|c|c|c|c|c|c|c|c|c|c|c|c|}
\hline \multicolumn{4}{|c|}{ EU-1 panel } & \multicolumn{3}{|c|}{ EU-2 panel } & \multicolumn{3}{|c|}{ EU-3 panel } & \multicolumn{3}{|c|}{ EU-4 panel } \\
\hline Variables & $\mathrm{Chi}^{2}$ & $\mathrm{df}$ & $p$ value & $\mathrm{Chi}^{2}$ & $\mathrm{df}$ & $p$ value & $\mathrm{Chi}^{2}$ & $\mathrm{df}$ & $p$ value & $\mathrm{Chi}^{2}$ & $\mathrm{df}$ & $p$ value \\
\hline Log_ER_55_64 & 368.65 & 6 & 0.000 & 80.93 & 6 & 0.000 & 138.21 & 6 & 0.000 & 551.39 & 6 & 0.000 \\
\hline $\log _{-} L P$ & 1.15 & 1 & 0.2840 & 0.21 & 1 & 0.6493 & 18.46 & 1 & 0.000 & 6.31 & 1 & 0.0120 \\
\hline Log_GDP_C & 544.83 & 4 & 0.000 & 3981.66 & 4 & 0.000 & 1169.88 & 4 & 0.000 & 83.35 & 4 & 0.000 \\
\hline Log_POV_R_65 & 8.03 & 1 & 0.0046 & 0.20 & 1 & 0.0508 & 63.73 & 1 & 0.000 & 24.86 & 1 & 0.000 \\
\hline
\end{tabular}

$H_{0}$ : All coefficients excluding the intercept are 0 . We can thus reject the null hypothesis for each equation, with limitation on LP. Source: authors' process.

TABLE 3: Goodness-of-fit tests for the SEM models, EU-27, 1995-2018.

\begin{tabular}{|c|c|c|c|c|}
\hline & EU-1 panel & EU-2 panel & EU-3 panel & EU-4 panel \\
\hline \multicolumn{5}{|c|}{ Likelihood ratio } \\
\hline Model vs. saturated chi $^{2} \_$ms (30) & 842.038 & 847.432 & 766.993 & 512.168 \\
\hline$p>\operatorname{chi}^{2}$ & 0.000 & 0.000 & 0.000 & 0.000 \\
\hline Baseline vs. saturated chi $^{2}$ _bs $(42)$ & 1303.435 & 1497.824 & 1156.007 & 797.052 \\
\hline$p>$ chi $^{2}$ & 0.000 & 0.000 & 0.000 & 0.000 \\
\hline \multicolumn{5}{|c|}{ Population error } \\
\hline RMSEA (root mean squared error of approximation) & 0.394 & 0.315 & 0.406 & 0.360 \\
\hline $90 \%$ CI, lower bound & 0.372 & 0.297 & 0.381 & 0.333 \\
\hline Upper bound & 0.418 & 0.334 & 0.431 & 0.388 \\
\hline Pclose (probability RMSEA $\leq 0.05$ ) & 0.000 & 0.000 & 0.000 & 0.000 \\
\hline \multicolumn{5}{|c|}{ Information criteria } \\
\hline AIC (Akaike's information criterion) & 496.177 & 615.809 & 100.296 & -1084.422 \\
\hline BIC (Bayesian information criterion) & 730.371 & 883.450 & 323.083 & -875.127 \\
\hline \multicolumn{5}{|c|}{ Baseline comparison } \\
\hline CFI (comparative fit index) & 0.356 & 0.439 & 0.338 & 0.361 \\
\hline TLI (Tucker-Lewis index) & 0.099 & 0.214 & 0.074 & 0.106 \\
\hline \multicolumn{5}{|c|}{ Size of residuals } \\
\hline CD (coefficient of determination) & 0.947 & 0.902 & 0.806 & 0.862 \\
\hline
\end{tabular}

Source: own research.

TABle 4: Cronbach's Alpha for the SEM models, EU-27, 1995-2018.

\begin{tabular}{|c|c|c|c|c|c|c|c|c|}
\hline \multirow[b]{2}{*}{ Items } & \multicolumn{2}{|c|}{ EU-1 panel } & \multicolumn{2}{|c|}{ EU-2 panel } & \multicolumn{2}{|c|}{ EU-3 panel } & \multicolumn{2}{|c|}{ EU-4 panel } \\
\hline & $\begin{array}{l}\text { Item-test } \\
\text { correlation }\end{array}$ & Alpha & $\begin{array}{l}\text { Item-test } \\
\text { correlation }\end{array}$ & Alpha & $\begin{array}{c}\text { Item-test } \\
\text { correlation }\end{array}$ & Alpha & $\begin{array}{l}\text { Item-test } \\
\text { correlation }\end{array}$ & Alpha \\
\hline Log_EARN & 0.6791 & 0.7651 & 0.7834 & 0.8119 & 0.7293 & 0.8199 & 0.1624 & 0.8246 \\
\hline Log_ALMP & 0.7990 & 0.7545 & 0.5726 & 0.8324 & 0.8508 & 0.8185 & 0.5808 & 0.7895 \\
\hline Log_PLMP & 0.7954 & 0.7561 & 0.7444 & 0.8192 & 0.6355 & 0.8327 & 0.3309 & 0.8089 \\
\hline Log_EDU_acq & 0.2780 & 0.8133 & 0.4689 & 0.8373 & 0.7718 & 0.8180 & 0.6840 & 0.7803 \\
\hline Log_GERD & 0.7262 & 0.7665 & 0.5298 & 0.8351 & 0.8192 & 0.8112 & 0.7542 & 0.7601 \\
\hline Log_Active_pop & 0.8369 & 0.7499 & 0.4255 & 0.8438 & 0.6832 & 0.8247 & 0.7033 & 0.7635 \\
\hline Log_BR & 0.0382 & 0.8318 & 0.3135 & 0.8521 & 0.1252 & 0.8635 & 0.6466 & 0.7756 \\
\hline Log_LE & 0.7565 & 0.7592 & 0.9170 & 0.7973 & 0.4746 & 0.8460 & 0.5419 & 0.7937 \\
\hline Log_OD_65 & 0.0518 & 0.8328 & 0.7088 & 0.8206 & 0.7129 & 0.8235 & 0.5705 & 0.7840 \\
\hline Log_ER_55_64 & 0.3059 & 0.8112 & 0.4796 & 0.8430 & 0.2736 & 0.8596 & 0.6189 & 0.7836 \\
\hline Log_LP & 0.7123 & 0.7683 & 0.7285 & 0.8198 & 0.6349 & 0.8302 & 0.4643 & 0.7986 \\
\hline Log_GDP_C & 0.6883 & 0.7707 & 0.8555 & 0.8044 & 0.6536 & 0.8298 & 0.7251 & 0.7653 \\
\hline Log_POV_R_65 & 0.4881 & 0.7885 & 0.2255 & 0.8548 & 0.5990 & 0.8339 & 0.3859 & 0.8006 \\
\hline Total scale & & 0.7980 & & 0.8407 & & 0.8434 & & 0.8012 \\
\hline
\end{tabular}

Source: own research.

Vignoli, and Lazzeretti [34] for Italy, which revealed that economic complexity based on employment data and fertility rate is favorable), while life expectancy $(L E)$ and old dependency ratio (OD_65) positively influenced GDP_C. The direct implications of population dimensions ( $B R$ and $L E)$ have generated beneficial impacts upon economic welfare for the EU-2 countries (the estimated coefficients are positive). For the EU-3 panel, LE was positively associated with GDP_C (the estimated coefficient is 8.192), while OD_65 has induced unfavorable impact on economic development, which suggest that the population over 65 is not very well supported by the working force (aged 15-64 years). 
For the EU-4 panel, none of the ageing credentials is not relevant from the statistical point of view (due to low data enclosed into this panel, with only 4 countries). Hereby, we can substantiate that the 2 nd hypothesis, $\mathrm{H}_{2}$ : Ageing dimensions and labor productivity significantly shape the economic development of the EU countries, visibly distinguished across the four panels of EU MS, is fulfilled.

Finally, the overall integrative results unveil that the economic welfare, reflected by the GDP_C, under direct and indirect influences of ageing credentials and labor market factors, positively influenced older people poverty $\left(P O V \_R \_65\right)$, in EU-1, EU-3, and EU-4 panels (Figures 5(a), 5(c), and 5(d)) (the estimated coefficients are negative, $-6.087,-11.75$, and -15.98 , respectively). For the EU-2 panel, the results are not relevant from the statistical point of view. Thereby, linked with the previous results from the literature, our findings are supported by the ones obtained by Cristea et al. [5] (p. 1367), which attested that "poverty is diminished for all considered EU panels under the sheer implications of selected factors," namely, labor productivity and ageing dimensions. Moreover, as regards the life expectancy, there are findings that proved that "the poor tend to die much earlier than the rich (...) This enormous gap translates into a difference in life expectancy of more than 13 years between the lowest and highest income quintiles" [37] (p. 1). Therefore, our 3rd hypothesis, $H_{3}$ : There are overall (direct, indirect, total) significant and diverse implications of economic development upon older people's poverty levels under the influence of the ageing credentials and labor market factors, across the four panels of EU MS, is fulfilled.

To put in a nutshell, in countries with the lowest AAI ranks (EU-1), the economic development $\left(G D P \_C\right)$ requires proper policies and strategies in terms of birth rate encouraging, sustaining life expectancy by active and healthy ageing strategies, a better engagement on the labor market of the 55-64 years aged people, and long life learning programs for ensuring updating skills and competencies for the ageing workforce.

Similar results had been highlighted by other authors, as Nagarajan, Teixeira, and Silva [15] and Kotschy and Sunde [14] also proved. These policies and strategies should be clearly drawn for each of the four groups of the EU countries (clustered according to AAI scores).

\section{Concluding Remarks}

Given the significance of the ageing support around the world within the framework of an increased life expectancy and a decreased birth rate, our general objective is to appraise the ageing dimensions and labor market credentials in conjunction with economic welfare (measured by GDP per capita and older people's poverty) within the EU-27 MS, deepened on four distinctive panels, mapped by the UNECE/EC [16] according to the active and healthy ageing strategies (AAI scores). The research endeavor consisted in testing three hypotheses, by applying structural equations modelling, for each specific group of the EU MS (below the EU average, medium low and upper EU average, and the highest scores).
Thereby, for the 1st group of countries that comprises the EU MS with AAI scores below the EU average (Greece, Croatia, Romania, Hungary, Slovenia, Poland, Bulgaria, Slovakia, Italy, and Spain), related to each hypothesis and the results obtained, we propose specific strategies and policies. As regards the favorable implication of the employment rate of the 55-64 years' aged group (ageing workforce) on labor productivity under the influence of other economic and social factors $\left(H_{1}\right)$, we propose the following measures: further improving earnings level, especially pension income in Bulgaria and Romania, as Walker and Zaidi [17] mention; a keen need for accurate measures designed to a massive rethinking of active labor market policies, such as training programs, job placement, and centers for career counselling (since total labor force stock and active labor market policies generated negative impacts on older workforce integration), extending the good practices of these policies applied in Denmark and Sweden (significant share in GDP, the highest implications revealed by SEM applied for panel EU-4); sustained $R \leftrightarrow D$ expenditures, especially for the workplace of people aged 55-64 years; adequate job creation for the elderly workforce in order to enhance labor productivity, namely, "by introducing age-friendly work environments" [17] (p. 43); and rethinking of the educational attainment by lifelong educational programs for specific skills enhancement of older workers. As regards ageing dimensions and labor productivity impacts upon economic development of these countries $\left(\mathrm{H}_{2}\right)$, we propose the following policies: reconsideration for sustaining the birth/fertility rate, "more associated with an area's typical specialization (agriculture, industry, or services)" of a country, as Innocenti, Vignoli, and Lazzeretti [34] suggested for Italian provinces; improving labor productivity under the impact of digital transformation, external benefits [38], and all of the considered economic and social factors. Regarding the overall implications of economic development in these countries upon older people's poverty under the influence of the ageing credentials and labor market factors in these countries $\left(\mathrm{H}_{3}\right)$, which were favorable, further sustaining of these dimensions jointly with independent and healthy living dimension of the AAI [16] (poverty credentials being considered for this domain by the UNECE/EC) is more than necessary, especially on the fact that the majority of the countries from this group registered the higher poverty rate of older people (Figure 1(b)).

As for the 2nd group of countries that comprises the EU countries with AAI scores upper low of the EU average (Luxembourg, Malta, Cyprus, Austria, Belgium, and France), related to ageing workforce on labor productivity under the influence of other economic and social factors $\left(H_{1}\right)$, there is a keen need for policies and strategies that also account for a reconsideration of the educational programs, along with active labor market policies, such as career advice for older workforce, training, incentives, and better workplace capable of providing a higher employers flexibility (to straighten their negative effects). Also, we acknowledge that, for this group of countries, among the four domains of the AAI, the employment component of older people presented the highest challenges [16] (p. 23). As regards the ageing 
dimensions and labor productivity impacts upon economic development $\left(\mathrm{H}_{2}\right)$ and, overall, upon older people's poverty $\left(H_{3}\right)$, we note that a further support of the active ageing dimensions and labor productivity is required (the results for these hypotheses were favorable).

The strategies and policies addressed to the 3rd group of countries that comprises the EU countries with AAI scores upper medium of the EU average (Lithuania, Portugal, Latvia, the Czech Republic, Estonia, Ireland, and Germany), related to ageing workforce on labor productivity under the influence of other economic and social factors $\left(H_{1}\right)$, are the following: better incentives to encourage longer labor market participation, especially for the 55-64 years' group of people with all levels of education (active labor market policies rethinking), decreasing benefits through public retirement schemes that incentivize employees to exit the labor market much earlier than expected (passive labor market policies reconsideration due to negative implications), along with targeting the R\&D applications for 55-64 years' adequate job creation and specific skills reorientation. These measures will also induce spillover effects to hinder the older dependency ratio effects on economic development $\left(H_{2}\right)$ and to sustain their overall implications upon lessening older people's poverty $\left(\mathrm{H}_{3}\right)$ (the results for this hypothesis were favorable).

As regards the 4th group of countries, which encloses countries with the highest results of AAI scores among EU MS (Finland, the Netherlands, Denmark, and Sweden), the keen focus on strategies and policies is not as considerable as for the other panels, since the results of the considered hypotheses were favorable. Still, since the results for PLMPs implications on the employment rate of older people $\left(H_{1}\right)$ were unfavorable, these countries must center on a reconsideration of the passive labor market policies to improve ageing workforce and an active insertion on the labor market.

Overall, in the case of almost all panels (except the 2nd one as regards the statistical significance), the economic development induced positive effects on the welfare levels of older people, reflected by a lessening of elderly poverty $(65+$ years).

The main limitations of our research consisted in missing data and/or a relatively reduced data availability for some variables and, in some situations, a lower degree of statistical significance of the estimated coefficients. Moreover, the results are under the foreseen implications of SARS-CoV-2 pandemic on the ageing dimensions (especially, life expectancy). Other limitations may rely on the differences among countries (as regards their economies) included in each panel by the UNECE/EC [16], according with AAI clustering, especially for the 1st group (with Central and Eastern European Countries, CEEC, together with Italy and Spain that have different historical, socioeconomic, and demographic backgrounds, such as the longest life expectancy) and the 3rd group of countries (being included heterogeneous countries as regards their economy). Therefore, the policies and measures proposed may be influenced by this grouping. We acknowledge that further research will have to focus on the integrative index of active ageing analysis for each EU country, making a differentiation between life expectancy and healthy life expectancy at the level of each EU MS, in order to set distinctive policies. Also, we will consider the gender implications and the effects induced by COVID-19 infections.

\section{Data Availability}

The data used to support the findings of this study are available from the corresponding author upon request.

\section{Conflicts of Interest}

The authors declare that there are no conflicts of interest regarding the publication of this paper.

\section{Supplementary Materials}

Table A-Ia: Summary statistics, EU-1 panel, 1995-2018. Table A-Ib: Summary statistics, EU-2 panel, 1995-2018. Table A-Ic: Summary statistics, EU-3 panel, 1995-2018. Table A-Id: Summary statistics, EU-4 panel, 1995-2018. Figure A-I: Graphical mapping of AAI clustering for the countries considered in the empirical analysis, EU-27 Member States, 2018. Figure A-II: The welfare indicators, EU-27, 2018: (a) GDP_C. (b) POV_R_65. Figure A-III: The ageing indicators, EU-27, 2018: (a) BR. (b) LE. (c) OD_65. Figure A-IV: The main labor market indicators, EU-27, 2018: (a) LP. (b) ALMP. (c) PLMP. (Supplementary Materials)

\section{References}

[1] OECD, Live Longer, Work Longer. Ageing and Employment Policies, OECD Publishing, Paris, France, 2006.

[2] M. Cristea and A. Mitrică, "Global ageing: do privately managed pension funds represent a long term alternative for the romanian pension system? empirical research," Romanian Journal of Political Science, vol. 16, no. 1, pp. 63-106, 2016.

[3] European Commission, "Ready for the demographic revolution? measuring active ageing," 2016, https://ec.europa.eu/ social $/$ main.jsp?langId=en\&catId=752\&furtherNews=yes\&ne wsId=2430\#navItem- 1 .

[4] M. Káčerová and J. Mládek, "Population ageing as generation substitutions: economic and social aspects," Ekonomický časopis, vol. 60, no. 3, pp. 259-276, 2012.

[5] M. Cristea, G. G. Noja, D. E. Dănăcică, and P. Ştefea, "Population ageing, labour productivity and economic welfare in the european union," Economic Research-Ekonomska Istraživanja, vol. 33, no. 1, pp. 1354-1376, 2020.

[6] J. Song and D. Ryu, "Aging effects on consumption risksharing channels in european countries," Zbornik Radova Ekonomskog Fakulteta U Rijeci: Časopis za Ekonomsku Teoriju i Praksu, vol. 36, no. 2, pp. 585-617, 2018.

[7] K. Kinsella and D. R. Phillips, "Global ageing: the challenge of success," Population Bulletin, vol. 60, no. 1, pp. 3-40, 2005.

[8] WTO, "Active ageing: a policy framework," World Health Organization, Geneva, Switzerland, WHO/NMH/NPH/02.8, 2002.

[9] The World Bank, "World development indicators," 2020, https://databank.worldbank.org/reports.aspx?source=worlddevelopment-indicators. 
[10] European Commission and Eurostat Products Eurostat News, "Old-age dependency ratio increasing in the eu," 2020.

[11] S. S. Aiyar and C. Ebeke, The Impact of Workforce Aging on European Productivity, International Monetary Fund, Washington, DC, USA, 2016.

[12] D. E. Bloom, D. Canning, and G. Fink, "Implications of population ageing for economic growth," Oxford Review of Economic Policy, vol. 26, no. 4, pp. 583-612, 2010.

[13] M. Fougère and M. Mérette, "Population ageing and economic growth in seven OECD countries," Economic Modelling, vol. 16, no. 3, pp. 411-427, 1999.

[14] R. Kotschy and U. Sunde, "Can education compensate the effect of population ageing on macroeconomic performance?" Economic Policy, vol. 33, no. 96, pp. 587-634, 2018.

[15] N. R. Nagarajan, A. A. C. Teixeira, and S. T. Silva, “Ageing population: identifying the determinants of ageing in the least developed countries," Population Research and Policy Review, vol. 40, pp. 187-210, 2020.

[16] UNECE/European Commission, 2018 Active Ageing Index: Analytical Report, United Nations, New York, NY, USA, 2018, https://www.unece.org/fileadmin/DAM/pau/age/Active_ Ageing_Index/Stakeholder_Meeting/ACTIVE_AGEING_ INDEX_TRENDS_2008-2016_web_cover_reduced.pdf.

[17] A. Walker and A. Zaidi, "Strategies of active ageing in europe," in The Future of Ageing in Europe, A. Walker, Ed., Palgrave Macmillan, Singapore, pp. 29-52, 2019.

[18] OECD, Working Better with Age, Ageing and Employment Policies, OECD Publishing, Paris, France, 2019.

[19] European Commission, Active Ageing Index at the Local Level. Peer Review in Social protection and Social Inclusion 2015-2016, Directorate-General for Employment, Social Affairs and Inclusion, Population Unit of the UNECE and the European Centre for Social Welfare Policy and Research in Vienna, Berlin, Germany, 2016.

[20] A. Zaidi, Active Ageing Index: a Legacy of the European Year 2012 for Active Ageing and Solidarity Between Generations, European Centre (Policy Brief 4), Vienna, Austria, 2015.

[21] European Commission, "Employment, social affairs \& inclusion. statistical data," 2020, https://ec.europa.eu/social/ main.jsp? catId=1143\&intPageId=3227\&langId=en.

[22] OECD, Ageing and Employment Policies: Denmark 2015: Working Better with Age, OECD Publishing, Paris, France, 2015.

[23] The European Foundation for the Improvement of Living and Working Conditions (Eurofound), “Ageing workforce," 2020, https://www.eurofound.europa.eu/topic/ageing-workforce.

[24] P. Johnson, "The impact of ageing: the supply of labour and human capital," in Economic Policy for Aging Societies, S. Horst, Ed., Springer, Berlin, Germany, 2002.

[25] S. Dixon, "Implications of population ageing for the labor market," Labour Market Trends, vol. 111, no. 2, pp. 67-76, 2003.

[26] R. Guest and K. Shacklock, "The impending shift to an older mix of workers: perspectives from the management and economics literatures," International Journal of Organisational Behaviour, vol. 10, no. 3, pp. 713-728, 2005.

[27] J. Feyrer, "Aggregate evidence on the link between age structure and productivity," Population and Development Review, vol. 34, pp. 78-99, 2008.

[28] A. E. Von Gaessler and T. Ziesemer, "Optimal education in times of ageing: the dependency ratio in the Uzawa-Lucas growth model," The Journal of the Economics of Ageing, vol. 7, pp. 125-142, 2016.
[29] A. Börsch-Supan and M. Weiss, "Productivity and age: evidence from work teams at the assembly line," Journal of the Economics of Ageing, vol. 7, pp. 30-42, 2016.

[30] B. F. Jones, "Age and great invention," The Review of Economics and Statistics, vol. 92, no. 1, pp. 1-14, 2010.

[31] Y. Aksoy, H. S. Basso, T. Grasl, and R. P. Smith, Demographic Structure and Macroeconomic Trends, Banco de Espana Birkbeck Working Papers in Economics and Finance 1501, Madrid, Spain, 2015.

[32] P. A. Balland and R. Boschma, "Mapping the potentials of regions in europe to contribute to new knowledge production in industry 4.0 technologies," Regional Studies, vol. 55, pp. 1-15, 2021.

[33] E. Forsythe, L. B. Kahn, F. Lange, and D. Wiczer, "Labor demand in the time of COVID-19: evidence from vacancy postings and ui claims," Journal of Public Economics, vol. 189, Article ID 104238, 2020.

[34] N. Innocenti, D. Vignoli, and L. Lazzeretti, "Economic complexity and fertility: insights from a low fertility country," Regional Studies, vol. 55, pp. 1-15, 2021.

[35] European Commission, "Eurostat, database.," 2020, https:// ec.europa.eu/eurostat/data/database.

[36] G. G. Noja and M. Cristea, "Working conditions and flexicurity measures as key drivers of economic growth: empirical evidence for europe," Ekonomický Časopis, vol. 66, no. 7, pp. 719-749, 2018.

[37] V. Kufenko, K. Prettner, and A. Sousa-Poza, "The economics of ageing and inequality: introduction to the special issue," Journal of the Economics of Ageing, vol. 14, pp. 1-4, 2019.

[38] C. M. Barbu and S. Ponea, "Professional motivation and satisfaction. case study at Prexi com ltd," Journal of Advanced Research in Management, vol. 10, no. 2, pp. 85-97, 2019. 